\title{
Severe Damage of a Pile Group Due to Slope Failure
}

D E L Ong ${ }^{1}$; C F Leung ${ }^{2}$, Y K Chow ${ }^{3}$ and $\mathrm{T} \mathrm{G} \mathrm{Ng}{ }^{4}$

Abstract: A pile group consisting of four cast in-place concrete piles was instrumented to measure the induced bending moment along the piles due to excavation of an adjacent slope. The green field lateral soil movement profiles and the lateral pile deflection profiles were monitored by in-soil and in-pile inclinometers, respectively. The unexpected early arrival of rain storm prior to the year-end monsoon caused the failure of the slope which resulted in the severe damage of this pile group located at the slope crest. This paper examines the pre- and post-failure behavior of the pile group and it is demonstrated that considering the uncracked and cracked bending stiffness of the piles is vital when evaluating the progressive damage of the pile group due to slope failure.

(3)

Keywords: Bending moment; Pile Group; Deflection; Excavation; Lateral soil movement, Limiting soil stress, Back-analysis; Pile cracks

\footnotetext{
${ }^{1}$ Director (Acting), Research Centre for Sustainable Technologies, Faculty of Engineering, Science \& Computing, Swinburne University of Technology, Sarawak Campus, 93350 Kuching, Sarawak, Malaysia. E-mail: elong@swinburne.edu.my

${ }^{2}$ Professor, Centre for Soft Ground Engineering, Civil Engineering Dept., National University of Singapore, Singapore 117576. E-mail: ceelcf@nus.edu.sg

${ }^{3}$ Professor, Centre for Soft Ground Engineering, Civil Engineering Dept., National University of Singapore, Singapore 117576. E-mail: ceechow@nus.edu.sg

${ }^{4}$ Executive Director, GeoEng Consultants (S) Pte Ltd./ Golder Associates (S) Pte Ltd., Singapore 329983. E-mail: ngtg@golder.com.sg
} 


\section{Introduction}

A proposed 8-storey industrial building with a one-level basement car park was constructed on an approximately $15,000 \mathrm{~m}^{2}$ site in Singapore. An instrumented cast in-place concrete pile group comprising four $900-\mathrm{mm}$ diameter piles was constructed near to the proposed access road boundary. In order to facilitate the construction of an underground storage tank, excavation in front of the instrumented pile group with slope gradient of 1:2.5 (vertical:horizontal) was carried out in marine clay. The maximum excavation depth was about $6 \mathrm{~m}$ below the existing ground level. Due to the unexpected early arrival of rain storm prior to the year-end monsoon season, the slope failed and the resulting excessive soil movement led to failure of the instrumented pile group.

The failure of the instrumented pile group was characterized by relatively large pile deflections as a direct result of lateral soil movements due to the slope failure. The field data obtained was evaluated in detail to achieve a better understanding on the magnitude of limiting soil stress on a pile group to reinforce the findings from centrifuge model studies on excavation-induced soil movement on a single pile (Ong et al. 2006; Leung et al. 2006) and on pile groups (Ong et al. 2009, 2011). A numerical study was also conducted to back-analyze the field data to gain a deeper understanding of the complex soil-structure interaction behavior. It should be noted that the main focus of this paper is on the pile-group behavior when affected by lateral soil movements and not on the cause of the slope failure.

\section{Soil profile}

Standard penetration tests (SPT) and limited numbers of in-situ vane shear tests were carried out to investigate the underlying soft marine clay. Fig. 1 shows the plan view of the site with locations of Borehole $\mathrm{BH} 1$, installed instruments and the 
61 instrumented pile group at the site. The groundwater level was measured using a standpipe piezometer installed to a depth of $25 \mathrm{~m}$ and found to be $1 \mathrm{~m}$ below ground level prior to the commencement of excavation.

Fig. 2 shows the interpreted subsurface soil profile and the geotechnical properties. Underlying the $1 \mathrm{~m}$ thick fill layer was a $9 \mathrm{~m}$ thick very soft greenish grey marine clay of the Kallang Formation with standard penetration resistance ( $\mathrm{N}$ value) less than 4. The underlying Old Alluvium was $2.5 \mathrm{~m}$ thick and comprised loose clayey sand with $\mathrm{N}$ values of 5 and 14, followed by a 1 m thick medium dense sand with $\mathrm{N}$ values of 14 and 38. Subsequently, a $9.5 \mathrm{~m}$ thick dense clayey sand with $\mathrm{N}$ values ranging between 29 and 50 was found. BH1 was terminated in very dense clayey sand where SPT refusals were recorded.

\section{Instrumentation program and layout}

In view of anticipated excavation in front of the piles, a pile group consisting of four $900-\mathrm{mm}$ cast in-situ concrete bored piles was instrumented to measure the expected bending moment along the pile induced during and after the excavation. One front pile (nearer to the excavation) and one rear pile (further away from the excavation) were instrumented. Fig. 3 shows the plan and elevation views of the instrumented piles in relation to the excavation. The locations of the in-pile inclinometer and the strain gages are shown in Fig. 4. As it was expected that the pile segment within the marine clay layer would bend more than other segments, the elevations of the resistance-type strain gages along the two instrumented piles were planned accordingly. To ensure that the strain gages function well under harsh and damp conditions, they were carefully water-proofed using resin. The wires connecting the strain gages were properly buried underground before connecting to the strain meter which was programmed to automatically acquire the strain gage readings every 
866 hours. An in-pile inclinometer was also installed in a rear pile to measure its pile deflection profile. The conventional inclinometer casing was placed in the bored pile before concreting. After concreting, baseline readings were taken. The measured pile deflection profile could then be differentiated to derive the pile bending moment profile.

\section{Excavation sequence and construction events}

Fig. 5 shows schematically the key events over the 2-month excavation and construction period. Due to the unexpected early arrival of rain storm prior to the year-end monsoon season, the slope slipped overnight after excavation of only $3.5 \mathrm{~m}$ from the original ground level. Fig. 6 shows the slope failure at the location of instrumented pile group. Henceforth, Day 0 is denoted as the day that slope failure occurred. It should be noted that sheet piles and steel struts were installed at the toe of the slope to protect the nearby piles only when the soil movements became unexpectedly large, especially after the occurrence of the soil slip.

\section{Measured in-pile and in-soil inclinometer readings}

101 The in-pile inclinometer was installed in one of the rear piles prior to the occurrence of soil slip. The measured rear pile deflection profiles are presented in Fig. 7(a). However, the in-soil inclinometer was installed 5 days after the first soil slip and the lateral soil movement profiles using Day 5 readings as datum are shown in Fig.

105 7(b). At the end of the monitoring period, the maximum pile deflection and the

106 maximum lateral soil movement measured at the ground level were about $220 \mathrm{~mm}$ and $590 \mathrm{~mm}$, respectively.

It is noted that both the pile and soil movement profiles are generally

109 triangular in shape where the largest magnitudes are recorded at the ground level. The

110 figures also reveal that the magnitudes of pile deflection and lateral soil movements 
111 reduce with increasing depth until about $13 \mathrm{~m}$ depth. Below this depth, the

112 magnitudes of lateral pile and soil movements quickly diminish due to stiffer

113 resistance offered by the medium dense sand ( $\mathrm{N}$ value of 14$)$ to dense clayey sand $(\mathrm{N}$

114 value of 38$)$.

115 Fig. 8 shows a comparison between the measured lateral pile deflection and

116 the lateral soil movement at various depths over the excavation period. Since both the

117 in-pile and in-soil inclinometers were located at about the same distance from the

118 excavation, the in-soil inclinometer readings could be reasonably assumed as the

119 green field lateral soil movements. Green field soil movements are the natural

120 behavior of soil movement patterns in the absence of a pile. Prior to Day 14, the

121 differences in lateral pile deflections and soil movements seemed insignificant.

122 However, after Day 14, it was evident that the lateral soil movement exceeded

123 the pile deflection within the top $10 \mathrm{~m}$ soft marine clay layer. The difference between

124 soil movement and pile deflection became more significant as excavation progresses.

125 At this stage, large-strain shear deformations were experienced by the soft clay as the

126 propped sheet pile wall failed in mitigating the lateral soil movements triggered by the

127 soil slip and also active lateral soil stress had been fully mobilized. Therefore,

128 increasingly more soils became plastic and subsequently flowed past the piles as

129 evidenced by the increasingly larger lateral soil movements especially after the

130 excavation had reached at least $5 \mathrm{~m}$, as shown in Fig. 8.

\section{Ultimate and cracking moment capacities of pile}

132 As concrete is weak against tension, the concrete in the bored piles is expected

133 to crack when subject to large bending strain. As the bending rigidity (EI) of cracked

134 concrete would be smaller than that of uncracked concrete, the interpretation of 
135 bending moment along the pile would depend on the magnitudes of the bending

136 rigidity of concrete at different stages.

137 As the soil slip was not anticipated in the pile design, only nominal $0.5 \%$ steel

138 reinforcement (ultimate tensile strength $410 \mathrm{~N} / \mathrm{mm}^{2}$ ) was provided in the piles. For a

139 900-mm diameter bored pile, its ultimate bending moment capacity, $\mathbf{M}_{\mathrm{ult}}$, is

140 determined to be about $520 \mathrm{kNm}$. On the other hand, the cracking moment, $\mathrm{M}_{\mathrm{cr}}$, of the

141 pile can be calculated by Eq. (1) according to Kong and Evans (1987)

$$
M_{c r}=f_{c t} Z
$$

143 where

$144 \mathrm{f}_{\mathrm{ct}}=$ tensile strength of concrete in flexure or the modulus of rupture of concrete and equal to $0.623 \mathrm{f}_{\mathrm{c}}{ }^{0.5}(\mathrm{MPa})$

$146 \mathrm{f}_{\mathrm{c}}{ }_{\mathrm{c}}=$ characteristic strength of concrete Grade $35(\mathrm{MPa})$,

$147 \mathrm{Z}=$ section modulus $\left(=\mathrm{I}_{\mathrm{g}} / \mathrm{y}\right)$

$148 \quad \mathrm{I}_{\mathrm{g}}=$ gross moment of inertia

$149 \mathrm{y}=$ distance from the centroid of the section to the extreme fiber in tension

150 For the $900-\mathrm{mm}$ diameter bored piles, its cracking moment is determined to be 264

$151 \mathrm{kNm}$, which is about half of the pile ultimate moment value. Initial cracks would 152 develop along the pile once the cracking moment is reached.

\section{Moment of inertia}

\section{Gross or uncracked moment of inertia, $I_{g}$}

A pile nominally reinforced with $0.5 \%$ steel can be considered as a lightly

156 reinforced pile. Branson (1977) established that for lightly reinforced concrete

157 structures, the gross moment of inertia, $I_{g}$ of the section can be used without

158 considering the contribution of the steel reinforcement. The $I_{g}$ for a circular section is

159 given by 


$$
I_{g}=\frac{\pi d^{4}}{64}
$$

\section{$161 \quad$ Fully cracked moment of inertia, $\underline{I}_{\underline{c}}$}

163 calculate the cracked moment of inertia, $\mathrm{I}_{\mathrm{cr}}$, of a rectangular beam section, it is thus

164 assumed that the fully cracked moment of inertia, $I_{c r}$ for the circular bored pile can be

165 similarly represented based on the principle of conservation of cross-sectional area.

166 For a fully cracked section, the stresses in the steel and concrete are assumed to be

167 proportional to strain. The cracked moment of inertia, $\mathrm{I}_{\mathrm{cr}}$, of a rectangular section is

168 given by Kong and Evans (1987) as follows

$$
I_{c r}=b d^{3}\left[\frac{1}{3}\left(\frac{x}{d}\right)^{3}+\alpha_{e} \rho\left(1-\frac{x}{d}\right)^{2}+\alpha_{e} \rho^{\prime}\left(\frac{x}{d}-\frac{d^{\prime}}{d}\right)^{2}\right]
$$

170 where

$171 \quad \alpha_{e}=\frac{E_{s}}{E_{c}}($ modular ratio $)$

$172 \rho=\frac{A_{s}}{b d}($ ratio of compression steel)

$173 \quad \rho^{\prime}=\frac{A_{s}^{\prime}}{b d}($ ratio of tension steel $)$

$174 d=$ effective depth

$175 d^{\prime}=$ depth from compression zone to centroid of compression steel

$176 x=$ depth of neutral axis

$177 b=$ width of concrete section

178 According to Eqs. (2) and (3), the $I_{\mathrm{g}}$ and $\mathrm{I}_{\mathrm{cr}}$ of the $900-\mathrm{mm}$ bored pile are

$179 \quad 0.03221 \mathrm{~m}^{4}$ and $0.00607 \mathrm{~m}^{4}$, respectively.

180 Effective moment of inertia, $\underline{I}_{\underline{e}}$ 
182 the bending moment exceeds the cracking moment, $\mathrm{M}_{\mathrm{cr}}$, of the pile, cracks would start

183 to develop. Nevertheless, the depth and width of cracks may vary, depending on the

184 final bending moment distribution along the pile. As such, the moment of inertia for

185 this partially cracked section is somewhat between $I_{g}$ and $I_{c r}$ values. Therefore, an

186 effective moment of inertia, $\mathrm{I}_{\mathrm{e}}$, should be employed in the analysis of a partially

187 cracked section. By adopting an empirical equation proposed by Branson (1977),

188 Reese (1997) provided values of effective moment of inertia, $I_{e}$, that would reduce

189 gradually with increasing bending moment as follows

$$
I_{e}=\left[\frac{M_{c r}}{M}\right]^{3} I_{g}+\left[1-\left(\frac{M_{c r}}{M}\right)^{3}\right] I_{c r} \leq I_{g}
$$

191 where $\mathbf{M}_{\mathrm{cr}}$ and $\mathrm{M}$ are the cracking moment and applied moment, respectively.

\section{Curvature of pile shaft}

In the present study, the strain gages were fastened at the opposite faces of the

194 reinforcement cage and perpendicular to the excavation. As strain is a function of the stress and the Young's modulus of steel, $\mathrm{E}_{\mathrm{s}}$, the curvature, $\psi$, of the pile can be obtained from the sum (if different signs) or difference (if similar signs) in the

197 measured tensile strains, $\varepsilon_{t}$, and compressive strain, $\varepsilon_{c}$, of the steel reinforcement divided by the distance between them (Poh et al. 1999)

$$
\psi=\frac{\varepsilon_{t}-\varepsilon_{c}}{d-d^{\prime}}
$$

The 75-mm diameter in-pile inclinometer tube was fastened to the bored pile

201 reinforcement cage so that both the in-pile inclinometer tube and the pile would 202 deflect in unison when subject to lateral displacement. This would then provide a 
near-continuous set of data of pile curvature so as to deduce a more accurate and consistent bending moment profile.

In general, inclinometer readings are more reliable in determining the backanalyzed bending moments as compared to strain gage readings, as the inclinometer

207 readings obtained along a pile are near-continuous. Poh et al. (1999) established that 208 high order polynomials are necessary to fit the measured pile deflection profiles. In 209 the present study, a $7^{\text {th }}$ order polynomial function is found to be sufficient to obtain a 210 good fit between the measured and fitted deflection profiles. Subsequently, 211 differentiating the pile deflection profile twice would give the curvature along the 212 pile.

\section{Procedure to determine pile bending moment}

214 With the curvature and the bending stiffness of the pile determined, the 215 bending moment, M, can be calculated based on Macaulay's method (Kong and 216 Evans, 1987) as follows

$$
M=\psi E_{c} I_{e}
$$

218 In computing the bending stiffness, the value of Young's modulus $\mathrm{E}_{\mathrm{c}}$ is assumed to 219 remain constant (Reese, 1997). The $\mathrm{E}_{\mathrm{c}}$ for concrete used is taken as $32 \mathrm{GPa}$.

As both $\mathrm{M}$ and $\mathrm{I}_{\mathrm{e}}$ are mutually dependent [Eqs. (4) and (6)], an iterative 221 process is performed to obtain the two parameters. Starting from $I_{g}$, this value is then 222 substituted in Eq. (6) (where $\mathrm{I}_{\mathrm{e}}=\mathrm{I}_{\mathrm{g}}$ ). The $\mathrm{M}$ value obtained is then substituted in Eq.

223 (4). The $I_{e}$ value obtained is substituted back in Eq. (6). These iterative steps are 224 repeated until both $\mathrm{M}$ and $\mathrm{I}_{\mathrm{e}}$ register no further changes in values. This process is 225 repeated for all other elevations until the entire bending moment profile is determined. 
Fig. 9 shows several computed profiles of $I_{e}$ values along the length of the instrumented rear pile when subject to increasing lateral soil movements for various construction activities outlined in Fig. 5. Fig. 9 reveals some important observations:

a) On Day 0, when the $3.5 \mathrm{~m}$ deep excavated slope failed in front of the instrumented pile group, considerable increase in pile lateral deflections was observed all the way down to about $13 \mathrm{~m}$ depth. This depth corresponds to the soft marine clay $(\mathrm{N}<4)$ and loose clayey sand $(\mathrm{N}<10)$ strata. The lateral soil movements diminished beneath $13 \mathrm{~m}$ depth when medium dense to dense sand $(30<\mathrm{N}<50)$ was encountered.

b) The rate of decrease of $I_{e}$ values with respect to depth was the largest up to about $6 \mathrm{~m}$ depth which coincided with the final excavation depth in front of the instrumented pile. Within this depth, the development of cracks in the pile

c) Consistent patterns of concave (curved inwards) $I_{e}$ profiles are observed between depths of about $10 \mathrm{~m}$ and $17 \mathrm{~m}$ that correspond to the distinct change in soil layers from loose clayey sand $(\mathrm{N}=5)$ to dense sand $(\mathrm{N}=38)$. This aspect will be further addressed in the subsequent analysis of pile bending moment.

d) Further to the above observations, the rear pile seems to experience negative deflection (kick-back) within the dense and very dense sand strata. The pile kickback has an average magnitude of $2.6 \mathrm{~mm}$ with a maximum value of $3.8 \mathrm{~mm}$. It presumably due to the mobilization of passive resistances to resist the increasing lateral soil movements experienced by the upper portion of the pile.

\section{Equivalent effective moment of inertia, $\underline{I}_{\text {e(equiv) }}$}


As cracks gradually develop along the pile due to increase in excavation depth and thus increase in lateral soil movement, the moment of inertia of the pile is expected to deteriorate further. An "equivalent" or representative average $\mathrm{I}_{\mathrm{e}(\text { equiv) }}$ value on a particular day can be determined using the average $I_{e}$ values obtained between Day 0 of soil slip and the day of interest. Table 1 reveals that the magnitudes of the calculated $\mathrm{I}_{\mathrm{e}(\mathrm{equiv})}$ values based on the iterative calculation process described earlier, decrease over time due to increasing lateral soil movement imposed on the pile. Such a method has also been successfully used by Reese (1997) to analyze the crack behavior of laterally loaded piles. In many practical situations, the zone of maximum bending moment may occupy only a small fraction of the pile length. Reese (1997) reported that the errors due to the use of constant equivalent EI in the majority of regions of lower bending moment were deemed to be small. As such, the average $\mathrm{I}_{\mathrm{e}(\text { equiv) }}$ method shall be used in subsequent sections to back-analyze the effect of lateral soil movement on the pile using a well-established numerical method.

\section{Minimum deflection and bending moment initiating pile cracks}

As stated earlier, the cracking moment for the $900-\mathrm{mm}$ diameter bored piles is determined to be $264 \mathrm{kNm}$. By differentiating the appropriate measured pile deflection profile twice, the corresponding pile bending moment profile that initiates cracking can thus be back-analyzed as shown in Fig. 10. It is observed that the maximum positive pile bending moment occurs at $13.5 \mathrm{~m}$ depth which coincides with the distinct soil interface between depths of $10 \mathrm{~m}$ and $13.5 \mathrm{~m}$ as described earlier. At this soil interface, it is expected that the pile curvature changes abruptly due to a distinct increase in soil stiffness, thus inducing the maximum pile bending moment. Typically, pile heads are tied to the pile cap with relatively high percentage of steel. Therefore, despite experiencing bigger negative bending moment at the pile cap 
276 level as evidenced in Fig. 10, this is often not as critical as the maximum positive

277 bending moment developed along the lower pile shaft with only nominal steel

278 reinforcement.

\section{Observation of different degrees of cracking along pile length}

280 Different degrees of cracking along the length of the pile can be demonstrated 281 in Fig. 11, whereby the ratio of the back-analyzed bending moment, $\mathrm{M}$ and the 282 cracking moment, $\mathrm{M}_{\mathrm{cr}}$ is plotted against the ratio of the measured deflection, $\mathrm{D}$ and 283 the initial deflection at the onset of cracking, $D_{i}$ at various elevations for the back284 analyzed pile responses between Day 0 and Day 37.

285 It is evident that three distinct zones can be identified from Fig. 11. Zone 1 can 286 be identified as the zone whereby the pile experiences minimal cracking. This 287 coincides with data points measured at $15 \mathrm{~m}$ depth with dense clayey sand layer 288 having $\mathrm{N}$ value between 29 and 50. The higher resistance offered by the sand and the 289 attenuated lateral soil movements prevents the pile from being deflected excessively.

290 The measured data points in Zone 2 are obtained from the pile responses at 291 depths of $3 \mathrm{~m}, 5 \mathrm{~m}$ and $9 \mathrm{~m}$. It is evident that these data points are somewhat nestled 292 between the two extremes of Zones 1 and 3. These depths are dominated by the soft 293 marine clay with little soil resistance as compared to that of the sand in Zone 1. It is 294 deduced that cracking of the pile material is on-going for this zone.

295 Zone 3 represents the measured data points obtained from the pile responses at 296 depth of $12.5 \mathrm{~m}$, which approximately coincides with the soil interface as described 297 earlier where maximum pile bending moment develops. As such the $M / M_{c r}$ and $D / D_{i}$ 298 ratios are the greatest in Zone 3 as compared to those in Zones 1 and 2.

299 The pile behavior at different degrees of cracking shown in Fig. 11 shows 300 similar trends as those reported by Branson (1977). This bilinear moment-deflection 
301 curve suggests that the pile moment capacity reduces with increasing load levels and 302 the pile deflection increases in tandem with increasing degree of cracking of the pile 303 material. This would transform the relevant segment of the pile from an initial 304 uncracked pile (Zone 1) with minimal cracking to that of an intermediately cracked 305 pile segment (Zone 2) and finally to a fully cracked pile segment (Zone 3) whereby 306 significant cracking has taken place.

307 Based on the understanding above, the cracked pile can be physically 308 represented in a schematic plot as shown in Fig. 12(a) after having experienced lateral 309 soil movements for 37 days. In this case, the concrete between cracks may still be 310 capable of carrying some tension. As a result, the actual effective moment of inertia, $311 \mathrm{I}_{\mathrm{e}}$, will be somewhat in between the uncracked, $\mathrm{I}_{\mathrm{g}}$, and the fully cracked, $\mathrm{I}_{\mathrm{cr}}$ values. 312 Branson (1977) mentioned that in such a situation, the moment of inertia used to 313 represent the entire pile would be the average effective moment of inertia, $\mathrm{I}_{\mathrm{e}}$. The 314 significance of using an average $I_{e}$ value for the entire pile length is to ensure a 315 smooth bending moment profile. Such a method has also been used by Reese (1997) 316 to analyse the cracking behaviour of laterally loaded piles. The method used by Reese 317 (1997) employed the average observed deflection, the applied loading and iteration to 318 find the values of the average EI and the corresponding values of maximum bending 319 moment that fitted the results. Therefore, the average $\mathrm{I}_{\mathrm{e} \text { (equiv) }}$ values that have been 320 determined in Table 1 will now be used in the numerical back-analysis. The concept 321 of transforming the various moment inertia values of a pile due to varying crack 322 intensities to its idealized, single equivalent $\mathrm{I}_{\mathrm{e}(\text { equiv) }}$ value for back-analysis purpose, is 323 further illustrated in Fig. 12(b). 
The numerical method developed by Chow and Yong (1996) as described in

341 where Table 1. stress. detail in Ong et al. (2006) is used to back-analyze the measured field results. The pile is modeled as a series of linear elastic beam and the soil is idealized using the modulus of subgrade reaction. The numerical analysis requires the knowledge of the pile flexural rigidity, $\mathrm{E}_{\mathrm{p}} \mathrm{I}_{\mathrm{p}}$, the limiting soil pressures, $\mathrm{p}_{\mathrm{y}}$ that acts on the pile, the distribution of lateral soil stiffness, $\mathrm{K}_{\mathrm{h}}$ with depth and the lateral soil movement profile at the pile location. The rigidity of the pile cap is determined to be $2.7 \times 10^{7}$ $\mathrm{kNm}^{2}$. The modulus of elasticity for concrete, $\mathrm{E}_{\mathrm{c}}$, used is $32,040 \mathrm{MPa}$, while the moment of inertia values with respect to elapsed number of days can be found in

In most practical situations, the post-excavation vane shear strength profiles are usually not available. Leung et al. (2006) reported that the normalized limiting soil stress coefficient $P_{n}$ for piles subject to lateral soil movement along the pile shaft is lower and as given in Eq. (7) (unlike piles subject to lateral load at or above the ground level).

$$
\mathrm{P}_{\mathrm{n}}=\mathrm{p}_{\mathrm{y}} / \mathrm{c}_{\mathrm{u}}=6
$$

$\mathrm{p}_{\mathrm{y}}=$ limiting soil stress

$\mathrm{c}_{\mathrm{u}}=$ pre-excavation vane shear strength.

The problem in hand is very similar to the centrifuge model study reported by Leung et al. (2006) as both cases involve large-strain soil movement due to excavation failure in soft clay. The Singapore marine clay is modeled as having preexcavation vane shear strength, $c_{u}$, of $0.25 \sigma^{\prime}{ }_{\text {vo }}$, where $\sigma^{\prime}{ }_{\text {vo }}$ is the effective overburden 
350 related to the Young's modulus of the soil, $\mathrm{E}_{\mathrm{s}}$, (Chow and Yong 1996), as shown in 351 Eq. (8).

$$
\mathrm{K}_{\mathrm{h}} \cong \mathrm{E}_{\mathrm{s}}
$$

For lateral loading, $E_{s}$ of clay is assumed to range from $150 c_{u}$ to $400 c_{u}$

354 (Poulos and Davis 1980). In the present back analysis, $E_{\mathrm{s}}$ is taken as $300 \mathrm{c}_{\mathrm{u}}$. 355 Subsequent analyses reveal that the numerical calculation is not sensitive to the 356 magnitude of $\mathrm{E}_{\mathrm{s}} / \mathrm{c}_{\mathrm{u}}$ as the problem in hand involves large-strain soil movement. 357 Instead, the more sensitive parameter would be the $P_{n}$ ratio adopted in Eq. (7).

358 The input green field soil movement profiles are obtained from the in-soil 359 inclinometer readings shown in Fig. 7(b). However, based on the study of Ong et al. 360 (2009) and Lim (2001), a soil moderation factor should be considered for the rear 361 piles. Since the soil movement occurred first at the location nearer to the excavation 362 face, the front piles tend to shield the rear piles from the increasing soil movements 363 due to excavation. The progressive soil movements acting first on the front pile and 364 later on the rear pile have been captured schematically in Fig. 5. In the back-analysis 365 of centrifuge test results under similar soil and pile configuration, Ong et al. (2009) 366 established that a soil moderation factor of 0.7 should be applied to the soil movement 367 profile for the rear pile.

368 The evaluation of limiting soil stress, $\mathrm{p}_{\mathrm{y}}$ and the concept of average equivalent 369 effective moment of inertia, $\mathrm{I}_{\text {e(equiv) }}$ described above, shall now be validated using the 370 numerical method mentioned earlier.

\section{$371 \quad$ Calculated pile responses}

Figs. 13 and 14 show a comparison of measured and predicted pile bending moment and deflection profiles due to lateral soil movement from Day -1 to Day 14, 
374 and from Day 16 to Day 36, respectively. In general, it can be observed that the 375 shapes of the profiles and the locations of their maxima are in good agreement. It is 376 noted that the numerical prediction generally under-estimates the maximum negative 377 bending moment values at the pile cap level. The measured maximum negative 378 bending moments are much higher due to the stiffening effect caused by the provision 379 of greater steel reinforcement to connect the pile head to the pile cap during 380 construction. However, this stiffening effect could not be exactly modeled in the 381 numerical back-analysis.

382 Since there is no in-pile inclinometer in the front pile, only discrete bending 383 moment values measured by the strain gages are plotted for comparison in Figs. 13 384 and 14. The measured average strain gage readings used for the bending moment 385 interpretation are shown in Table 2. The measured bending moment values show 386 reasonably good agreement with the bending moment profiles predicted using the 387 numerical method.

388 Figs. 13 and 14 also show the measured deflection profiles of the rear pile, 389 which was instrumented with an in-pile inclinometer. It is observed that the shapes of 390 the measured and predicted rear pile deflection profiles are generally in good 391 agreement. Nonetheless, it has also been found that the rear pile deflection profiles 392 have been slightly under-predicted between Day -1 and Day 14 (see Fig. 13), but 393 slightly over-estimated between Day 16 and Day 36 (see Fig. 14). It is established that 394 the accuracy of the calculated pile deflection profiles depends on the soil moderation 395 factor used in the numerical back-analysis. Therefore, it is to be acknowledged that 396 the value of 0.7 currently adopted seems to be a suitable average value to produce 397 comparable predicted pile deflection profiles for all the calculated $I_{e}$ values in this 398 study. 
400 also included in Figs. 13 and 14. However, no comparison could be made because the

401 front pile was not instrumented with an in-pile inclinometer.

$402 \quad$ Before Day 15

403 For relatively small lateral soil movements, Ong et al. (2006) reported that the 404 calculated pile responses depend more on the values of bending stiffness $\mathrm{E}_{\mathrm{c}} \mathrm{I}$ adopted. 405 Since the calculated and measured pile bending moments and deflections are 406 generally comparable as illustrated in Fig. 13, the credibility of the computed average $407 \mathrm{I}_{\mathrm{e}(\text { equiv) }}$ values proposed in Table 1 (assuming $\mathrm{E}_{\mathrm{c}}$ to be constant) used for the numerical 408 back-analysis is therefore justified.

\section{$409 \quad$ From Day 16 onwards}

It was evident from Fig. 8 that from Day 15 onwards, the 9 m thick soft clay

411 had moved ahead of the pile. This relative movement was more pronounced 412 especially for the first $6 \mathrm{~m}$ soft clay stratum, which also coincided with the $5 \mathrm{~m}$ 413 excavation depth. This important observation points to the onset of the soil flow 414 phenomenon, where the soil stresses are expected to have reached their limiting 415 values. Such phenomenon had been observed and documented by Leung et al. (2006), 416 thus justifying the use of $P_{n}$ value of 6 in the numerical analysis, whereby reasonably 417 good agreement between calculated and measured pile responses had been 418 demonstrated (see Fig. 14).

419 Therefore from Day 15 onwards, it is strongly believed that the pile has fully 420 cracked at the Zone 3 segment as a result of increasingly larger lateral soil 421 movements. This observation is also supported by the fact that when $\mathrm{I}_{\mathrm{cr}}$ is used in the 422 numerical analysis from Day 15 onwards, reasonably good comparison between 423 calculated and measured pile responses can be observed, as demonstrated in Fig. 14. 
Fig. 14 also evidently shows that the ultimate rear pile bending moment (520

$425 \mathrm{kNm}$ ) is exceeded between Day 23 and Day 30. This postulation signifies that the 426 instrumented pile group was damaged by the excessive soil movement caused by the 427 failure of the clay slope. Therefore, the pile group is deemed unfit to carry the 428 designed column load and a replacement pile group is indeed necessary. In this case 429 study, the mobilization of pile axial load as a result of the soil movement could not be 430 practically measured from the current instrumentation program. Also, the numerical 431 method did not consider the possible development of additional axial load due to the 432 soil movement. Through observation, the soil movement occurred more significantly 433 in the lateral direction than the vertical direction. As such, it is expected that the 434 increase in the pile axial load will not be significant. In summary, Fig. 15 shows the deterioration of the pile moment of inertia 436 from an initially uncracked pile to a partially cracked pile and finally to a totally 437 cracked pile due to increasing lateral soil movement as the excavation depth 438 increased. When localized excavation was carried out between Day 8 and Day 14 to 439 expose some pile heads at the toe of the slope, the deterioration of the instrumented 440 pile moment of inertia was minimal. Subsequently, when further slope excavation was 441 carried out between Day 15 and Day 18, it was observed that the deterioration of pile 442 moment of inertia continued, but at a much faster rate. Finally, $\mathrm{I}_{\mathrm{cr}}$ was reached after 44316 days of excavation since the soil slip. From Fig. 15, it is obvious that the pile 444 moment of inertia varies due to cracking as a result of the progressive soil movements 445 experienced by the clay slope. If the variations in pile moment of inertia are not 446 considered in the analysis, the pile bending moment will be over-predicted and the 447 pile deflection will be under-predicted since the pile is assumed to be stiffer than what 
448 it is (Ong et al., 2010). This will result in an unrealistic and over-conservative back449 analysis.

\section{Conclusions}

451 The pre- and post-failure behaviors of a full-scale instrumented cast in-situ 452 concrete 4-pile group subject to excessive lateral soil movement triggered by a slope 453 failure are investigated in detail in this paper. The pile undergoes transformation from 454 initially an uncracked pile to one that is partially cracked and finally to a fully cracked 455 pile, due to large-strain lateral soil movement acting on the pile group over the 456 excavation period. With the progressive development of cracks along the pile, the 457 present study details a procedure in determining suitable average equivalent effective 458 moment of inertia, $\mathrm{I}_{\mathrm{e}(\text { equiv) }}$ values for use in the back-analysis of the field data.

459 It is established that the computed $\mathrm{I}_{\text {e(equiv) }}$ values and the normalized limiting ratio 460 of soil stress to vane shear strength, $\mathrm{P}_{\mathrm{n}}$, ratio of 6 as recommended by Leung et al. 461 (2006), are suitable to be employed in the numerical method adopting the green field 462 lateral soil movements to predict the behavior of the pile group subject to increasing 463 lateral soil movements. With reasonably good agreement between the measured and 464 predicted pile bending moment as well as deflection profiles, it thus reflects the 465 validity of combining the concepts of $\mathrm{I}_{\mathrm{e}(\text { equiv) }}$ and $\mathrm{P}_{\mathrm{n}}$. The consistency of the measured 466 pile behavior in the field with the results of the centrifuge tests conducted by Ong et 467 al. (2006, 2009) and Leung et al. (2006) has further reinforced the understanding of 468 the concept of soil limiting stress and the corresponding behavior of piles subject to 469 lateral soil movements.

\section{$470 \quad$ References}

471 Branson, D. E. (1977). Deformation of concrete structures. New York: McGraw-Hill. 
473 Chow, Y. K. and Yong, K. Y. (1996). "Analysis of piles subject to lateral soil 474 movements.” J. Inst. of Eng. Singapore, 36 (2), pp. 43-49.

475

476 Kong, F. K. and Evans, R. H. (1987). Reinforced and prestressed concrete. $3^{\text {rd }}$ 477 Edition. Van Nostrand Reinhold (U.K.) Co. Ltd.

478

479 Leung, C. F., Ong, D. E. L., and Chow, Y. K. (2006). "Pile behavior due to 480 excavation-induced soil movement in clay. II: Collapsed wall." J. Geotech. 481 Geoenviron. Eng., 132(1), pp. 45-53.

482

483 Lim, J. K. (2001). "Behaviour of piles subject to excavation-induced soil movement." 484 M.Eng Thesis, National University of Singapore.

486 Ong, D. E. L., Leung, C. F. and Chow, Y. K. (2006). "Pile behavior due to 487 excavation-induced soil movement in clay. I: Stable wall." J. Geotech. Geoenviron. $488 \quad$ Eng., 132(1), pp. 36-44.

489

490 Ong, D. E. L., Leung, C. F. and Chow, Y. K. (2009). "Behavior of Pile Groups 491 Subject to Excavation-Induced Soil Movement in Very Soft Clay”. J. Geotech. 492 Geoenviron. Eng., 135(10), pp. 1462-1474.

493

494 Ong, D. E. L., Leung, C. F. and Chow, Y. K. (2010). "Effect of limiting soil pressure 495 on pile group adjacent to a failed excavation". Proc. of Int. Conf. on Geotechnical 496 Challenges in Megacities, Moscow, Russia, Vol. 3, pp. 785-792. 
498 Ong, D. E. L., Leung, C. F. and Chow, Y. K. (2011). "Behavior of Pile Groups 499 Subject to Excavation-Induced Soil Movement in Very Soft Clay”. Discussion by F. 500 Castelli \& Closure, J. Geotech. Geoenviron. Eng., 137(1), pp. 110-113.

502 Poh, T. Y., Goh, A. T. C., Wong K. S., Wong, I. H. and Poh, K. B. (1999). 503 "Determination of BM in diaphragm wall." Field Measurements in Geomechanics, 504 Singapore, pp. 229-234.

505

506 Poulos, H. G., and Davis, E. H. (1980). Pile foundation analysis and design. John 507 Wiley \& Sons, New York.

508

509 Reese, L. C. (1997). "Analysis of laterally loaded piles in weak rock". J. Geotech. 510 Geoenviron. Eng., 33(11), pp. 1010-1017. 
Table 1. Computed average equivalent effective moment of inertia, $\mathrm{I}_{\mathrm{e}(\text { equiv) }}$ and fully cracked moment of inertia, $\mathrm{I}_{\mathrm{cr}}$

\begin{tabular}{|c|c|}
\hline $\begin{array}{l}\text { No. of days after first } \\
\text { soil slip }\end{array}$ & $\begin{array}{c}\text { Computed moment of inertia, } \\
\text { I }\left(\mathrm{m}^{4}\right)\end{array}$ \\
\hline Day -1 & $\mathrm{I}_{\mathrm{e}(\text { equiv })}=0.01921$ \\
\hline Day 1 & $\mathrm{I}_{\mathrm{e}(\mathrm{equiv})}=0.01486$ \\
\hline Day 9 & $\mathrm{I}_{\mathrm{e}(\text { equiv })}=0.01003$ \\
\hline Day 14 & $\mathrm{I}_{\mathrm{e}(\mathrm{equiv})}=0.01000$ \\
\hline Day 16 & \multirow{5}{*}{$\mathrm{I}_{\mathrm{cr}}=0.00616$} \\
\hline Day 18 & \\
\hline Day 19 & \\
\hline Day 23 & \\
\hline Day 30 & \\
\hline
\end{tabular}


Table 2. Measured average strain gage readings used for bending moment interpretation

\begin{tabular}{|c|c|c|c|c|c|c|c|c|}
\hline \multicolumn{9}{|c|}{ Average Strain, $\varepsilon$} \\
\hline & \multicolumn{4}{|c|}{ Depth of strain gage in instrumented Rear Pile } & \multicolumn{4}{|c|}{ Depth of strain gage in instrumented Front Pile } \\
\hline & $6 \mathrm{~m}$ & $8 \mathrm{~m}$ & $9 \mathrm{~m}$ & $11 \mathrm{~m}$ & $6 \mathrm{~m}$ & $8 \mathrm{~m}$ & $9 \mathrm{~m}$ & $11 \mathrm{~m}$ \\
\hline Day -1 & $2.55 \mathrm{E}-05$ & $2.15 \mathrm{E}-05$ & $-2.08 \mathrm{E}-04$ & $3.17 \mathrm{E}-04$ & $-4.50 \mathrm{E}-06$ & $-1.10 \mathrm{E}-05$ & $-1.39 \mathrm{E}-04$ & $2.35 \mathrm{E}-05$ \\
\hline Day 1 & $1.90 \mathrm{E}-05$ & 2.95E-05 & $-3.02 \mathrm{E}-04$ & $-7.55 \mathrm{E}-05$ & $-1.60 \mathrm{E}-05$ & $1.22 \mathrm{E}-04$ & $-1.12 \mathrm{E}-04$ & $6.40 \mathrm{E}-05$ \\
\hline Day 9 & $-2.66 \mathrm{E}-04$ & 2.98E-04 & 4.09E-04 & $6.69 \mathrm{E}-04$ & $-1.33 \mathrm{E}-03$ & $6.40 \mathrm{E}-05$ & $-8.05 \mathrm{E}-05$ & $1.05 \mathrm{E}-04$ \\
\hline Day 14 & $-6.69 \mathrm{E}-04$ & $2.11 \mathrm{E}-04$ & 4.11E-04 & 5.18E-04 & $-1.48 \mathrm{E}-03$ & $-4.71 E-04$ & $-1.03 \mathrm{E}-04$ & $1.14 \mathrm{E}-04$ \\
\hline Day 16 & $-6.66 \mathrm{E}-04$ & $2.22 \mathrm{E}-04$ & 2.84E-04 & $8.10 \mathrm{E}-04$ & $-1.52 \mathrm{E}-03$ & $-7.00 \mathrm{E}-04$ & $-8.85 \mathrm{E}-05$ & $1.24 \mathrm{E}-04$ \\
\hline Day 18 & $-6.74 \mathrm{E}-04$ & $1.93 \mathrm{E}-04$ & $3.97 \mathrm{E}-04$ & $9.93 \mathrm{E}-04$ & $-1.64 \mathrm{E}-03$ & $-1.11 \mathrm{E}-03$ & $-3.55 \mathrm{E}-05$ & $9.45 \mathrm{E}-05$ \\
\hline Day 23 & $-9.51 \mathrm{E}-04$ & $2.50 \mathrm{E}-06$ & 4.03E-04 & 1.19E-03 & $-1.71 \mathrm{E}-03$ & $-1.70 \mathrm{E}-03$ & $-1.25 \mathrm{E}-05$ & $-4.25 \mathrm{E}-04$ \\
\hline Day 30 & $-9.84 \mathrm{E}-04$ & $-8.30 \mathrm{E}-04$ & $4.11 \mathrm{E}-04$ & $1.02 \mathrm{E}-03$ & $-2.01 \mathrm{E}-03$ & $-2.19 \mathrm{E}-03$ & $5.60 \mathrm{E}-05$ & $-1.01 \mathrm{E}-03$ \\
\hline Day 36 & $-1.11 \mathrm{E}-03$ & $-2.67 \mathrm{E}-03$ & $3.29 \mathrm{E}-04$ & $1.02 \mathrm{E}-03$ & $-3.08 \mathrm{E}-03$ & $-2.17 \mathrm{E}-03$ & $-4.94 \mathrm{E}-04$ & $-1.03 \mathrm{E}-03$ \\
\hline
\end{tabular}




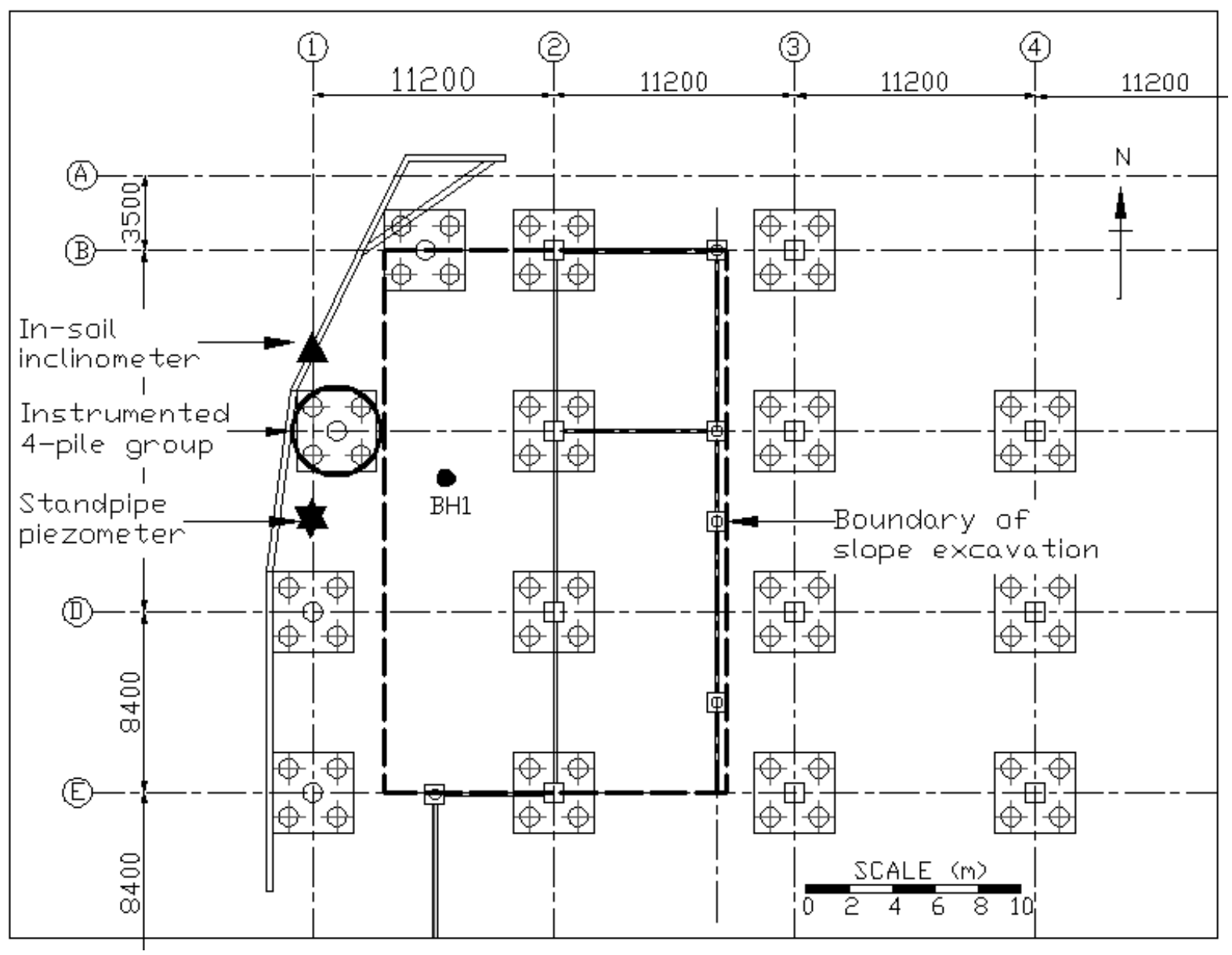

Fig. 1. Plan view showing the locations of instruments and instrumented pile group at the site 


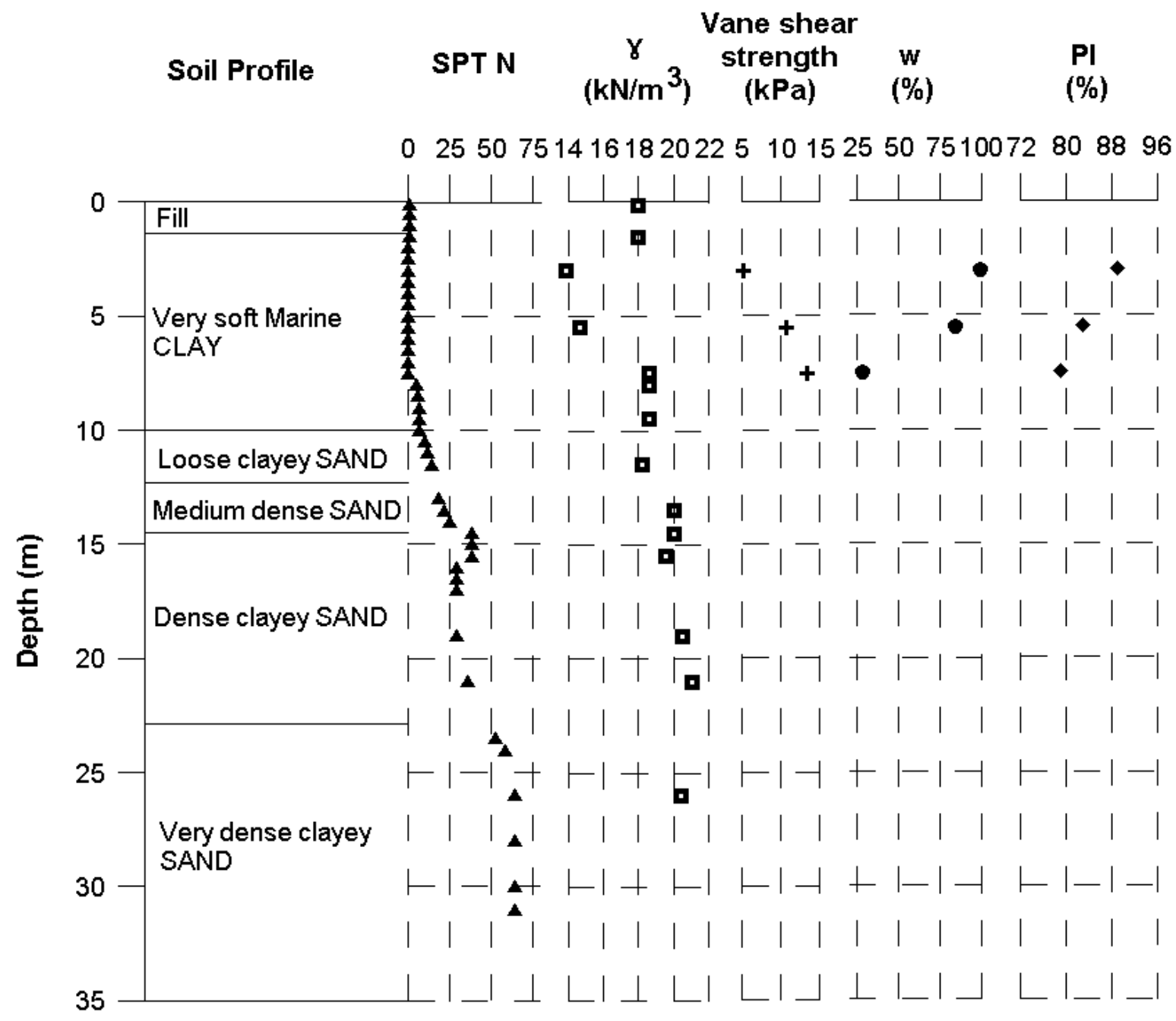

Fig. 2. Interpreted subsurface soil profile at site 

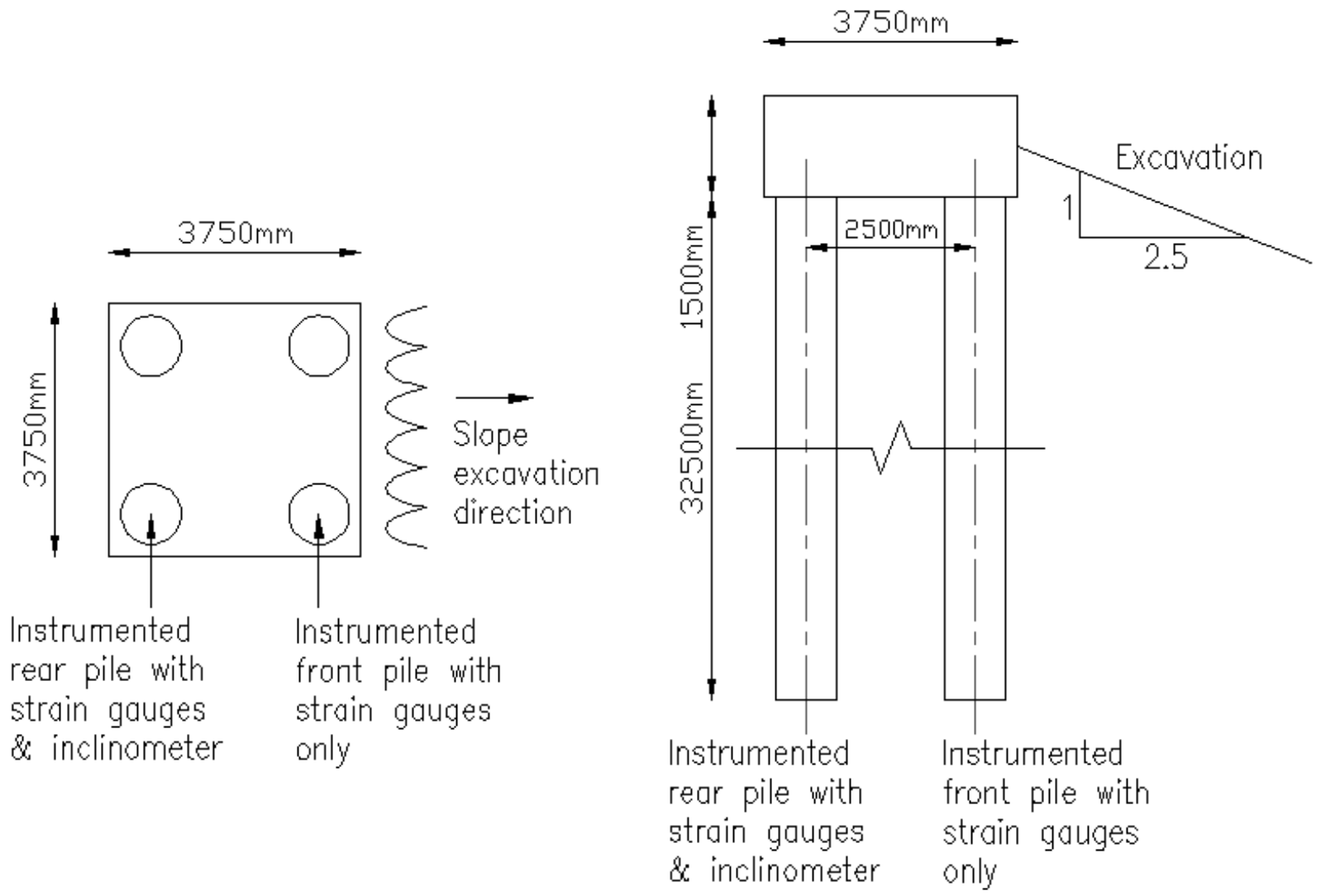

Fig. 3. Plan and elevation views of instrumented pile group with respect to the slope excavation 

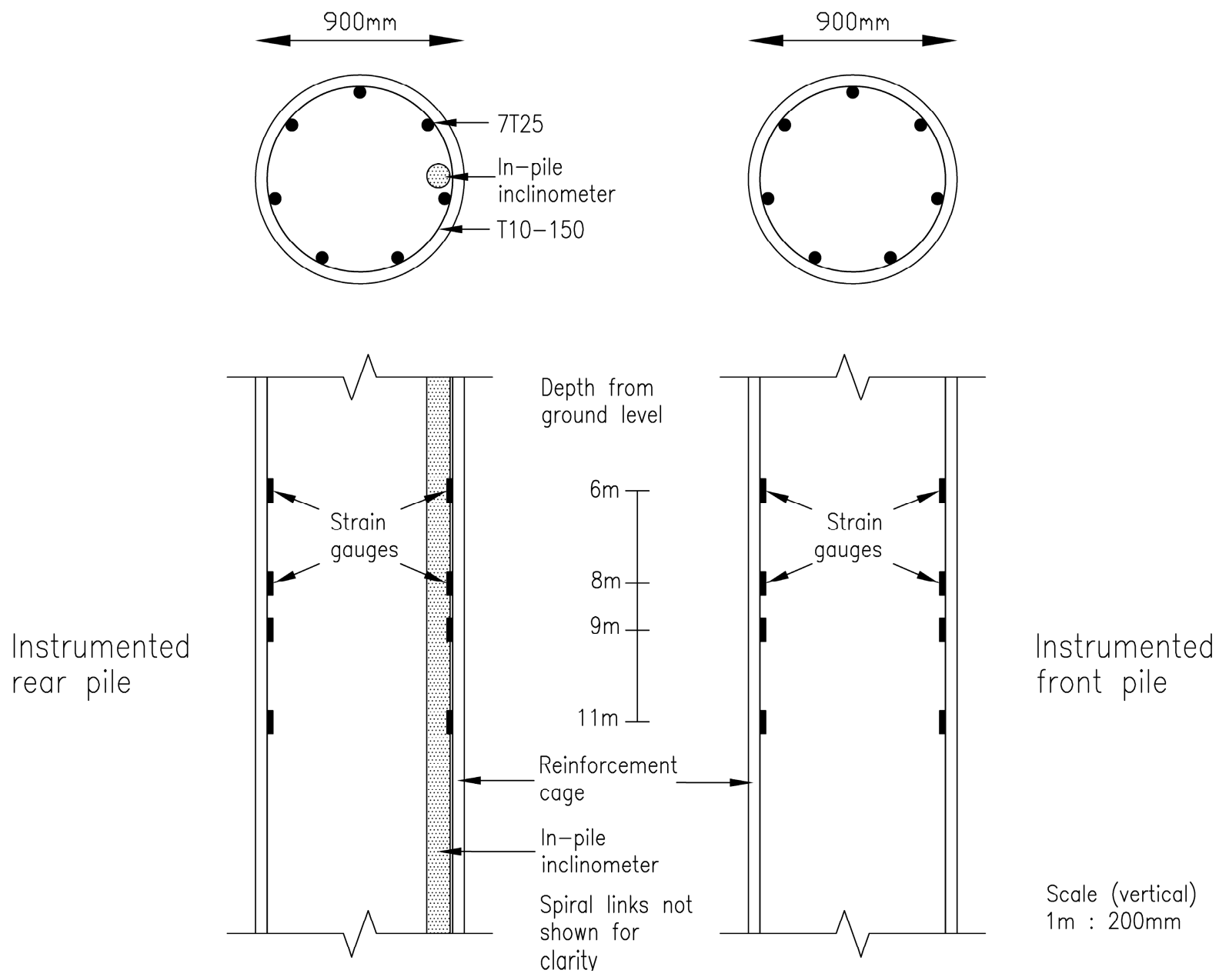

Fig. 4. Layout of instruments attached to reinforcement cages of the bored piles 


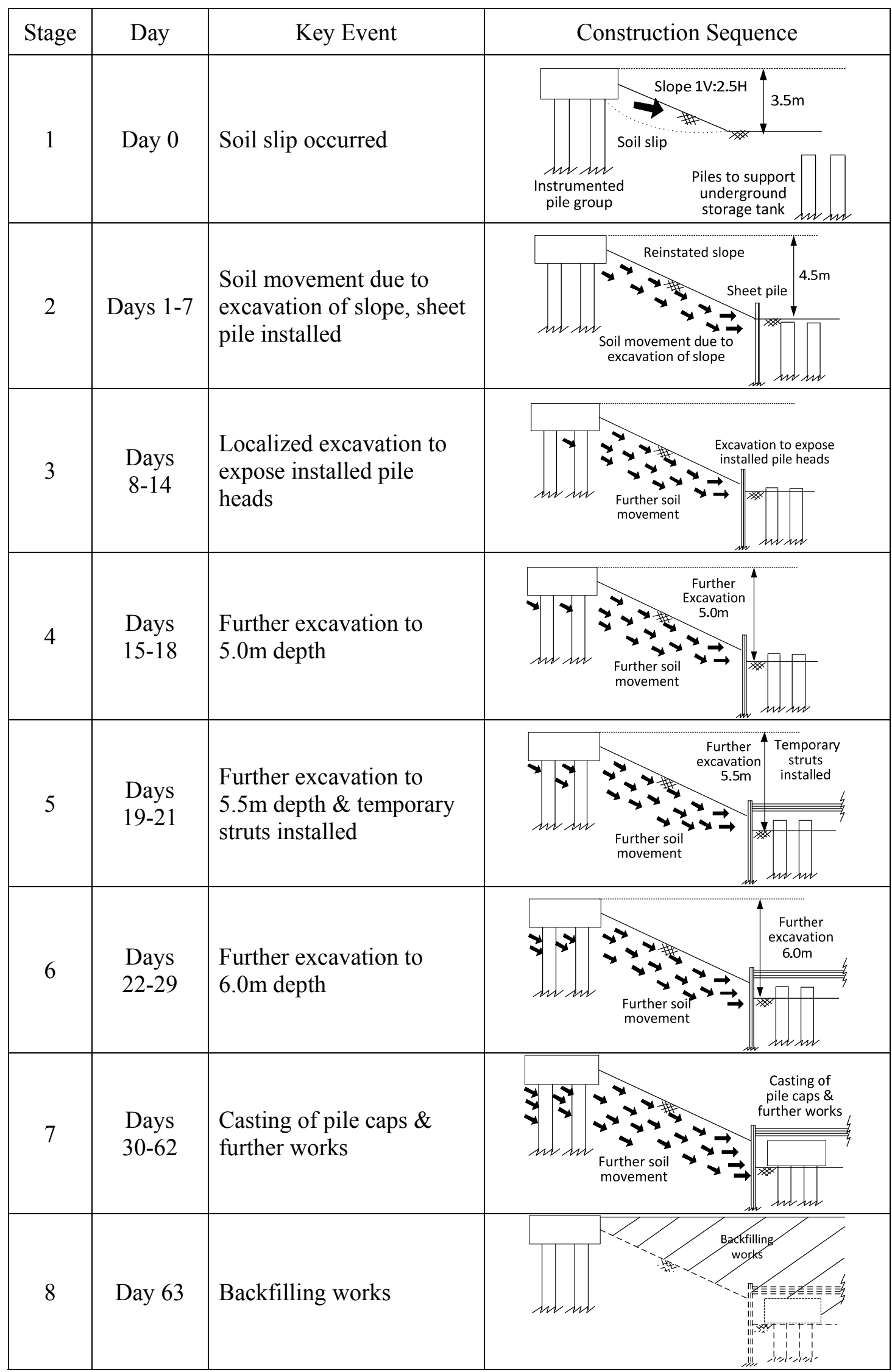

Fig. 5. Timeline of excavation works 


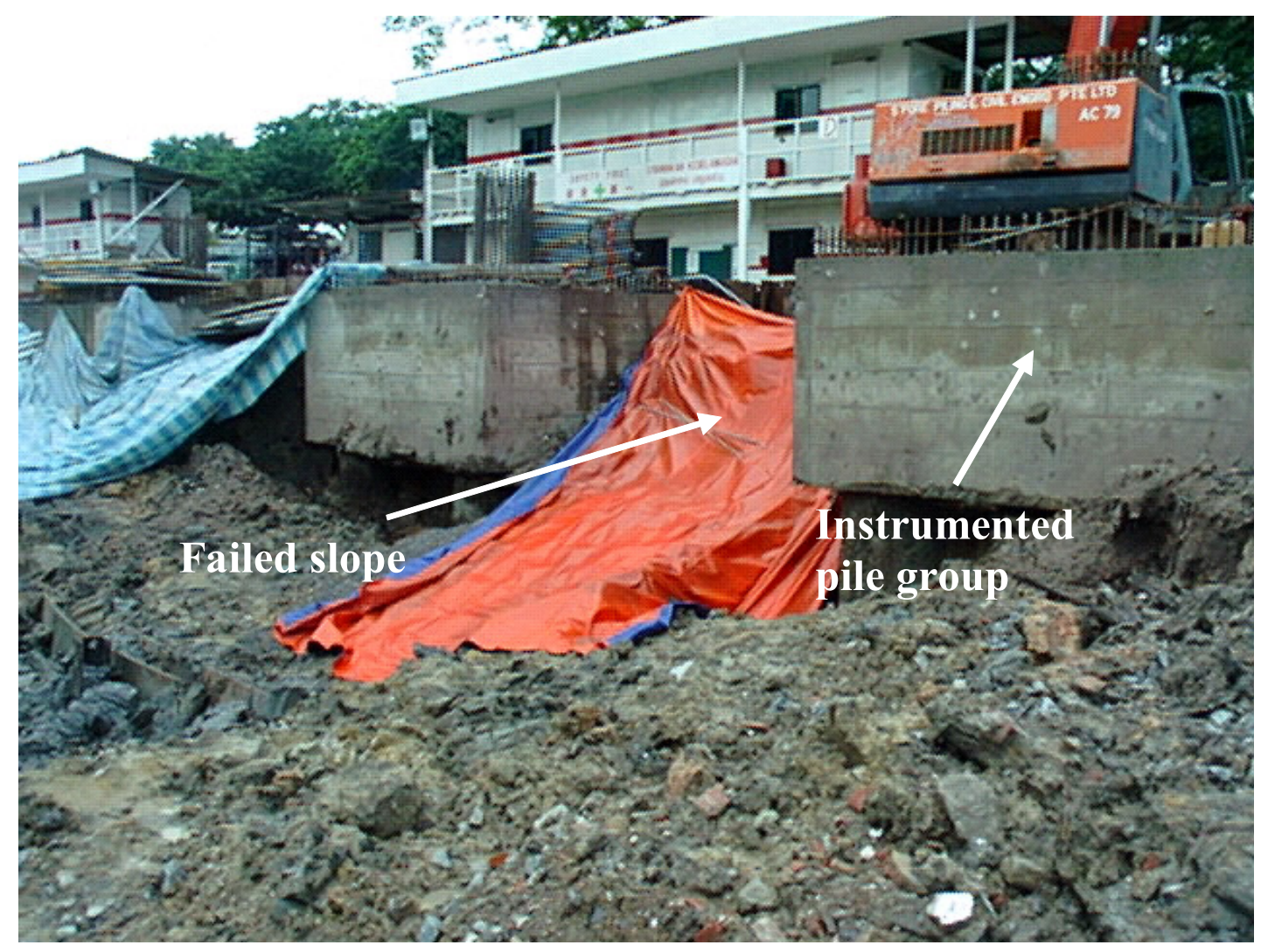

Fig. 6. Slope failure that unexpectedly occurred next to the instrumented pile group (Day 0) 


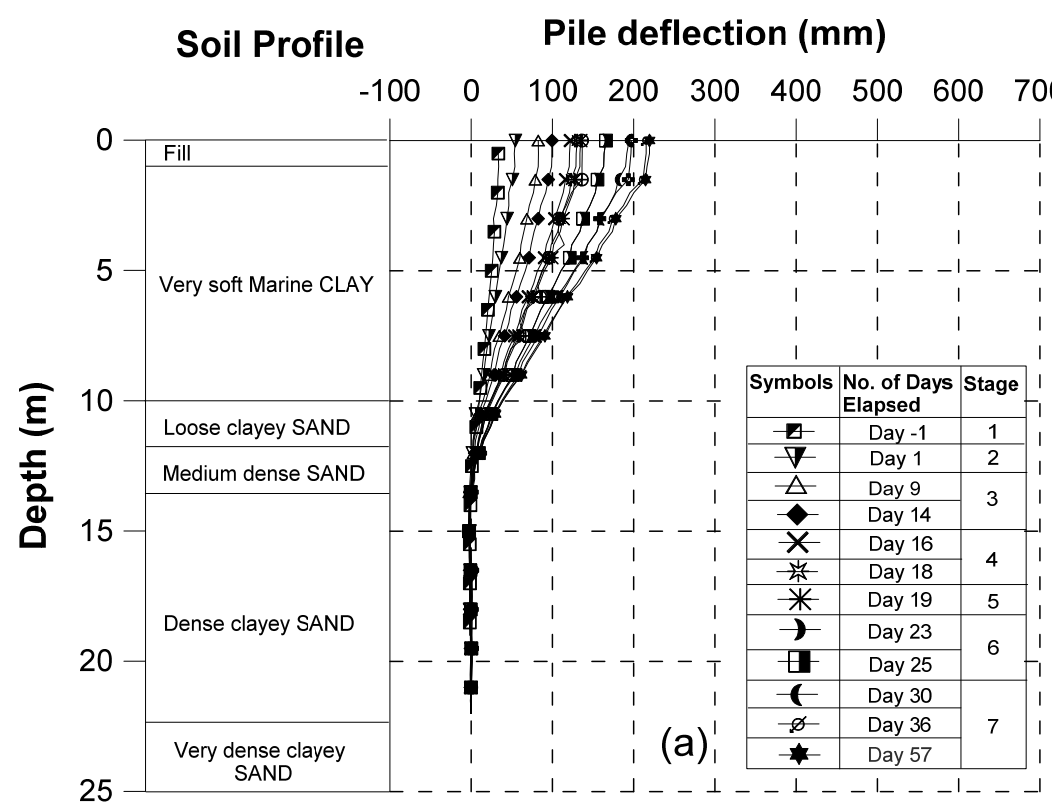

Note: Pile deflection has been observed even before the occurence of soil slip

\section{Lateral Soil Movement $(\mathrm{mm})$}

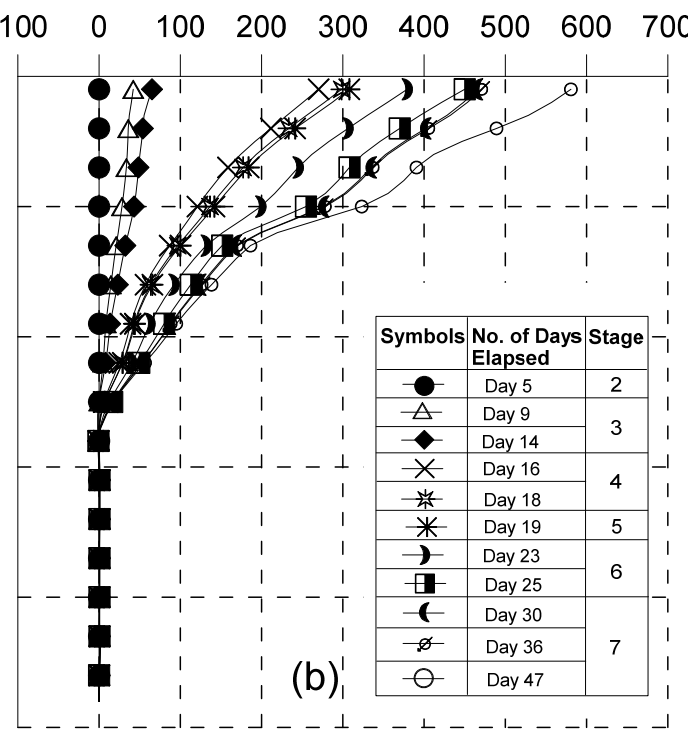

Note: First in-soil inclinometer reading was taken on Day 5

Fig. 7. Measured (a) rear pile deflection and (b) lateral soil movement profiles over the excavation period 


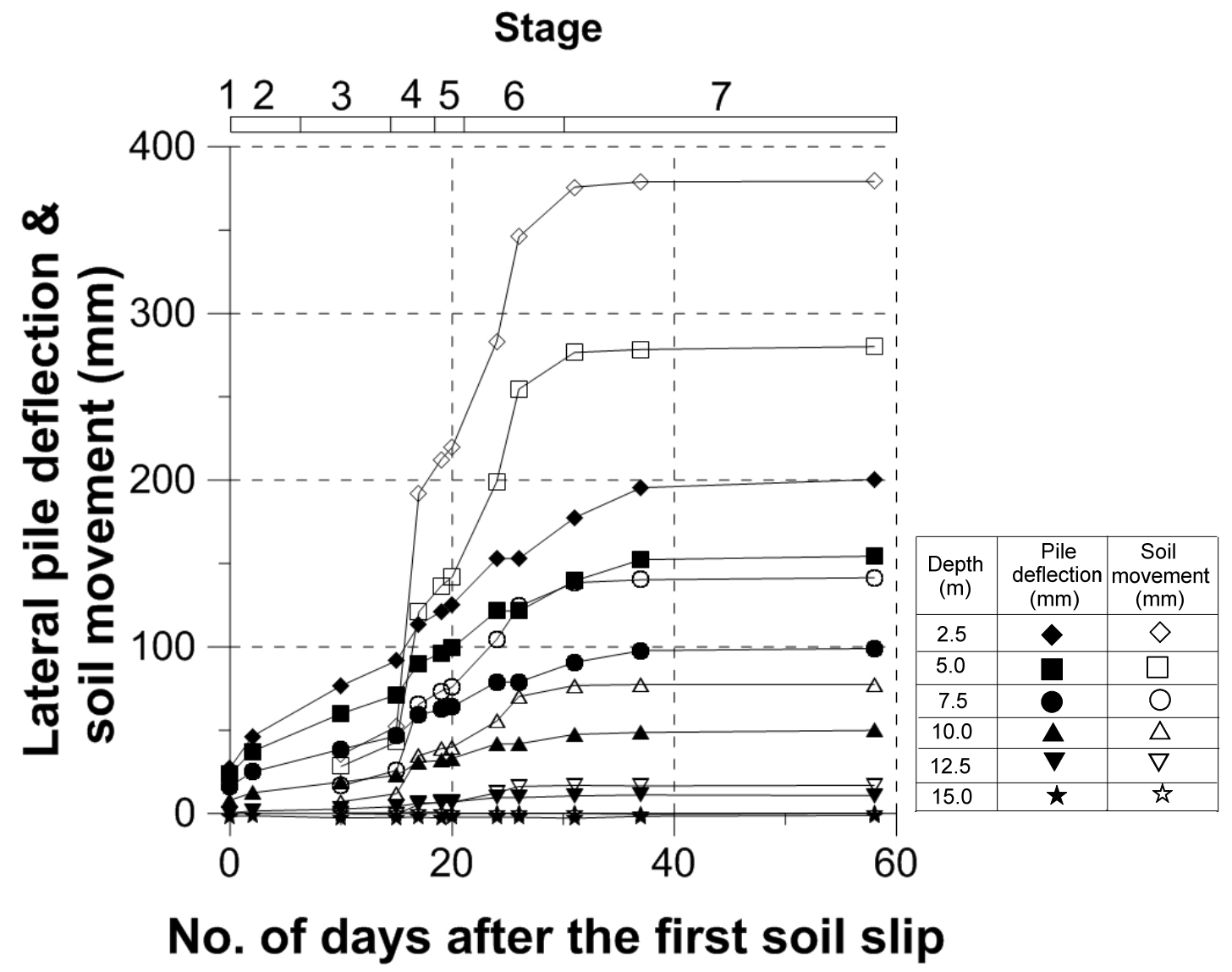

Fig. 8. Measured lateral pile deflection and soil movements at various depths over the excavation period 


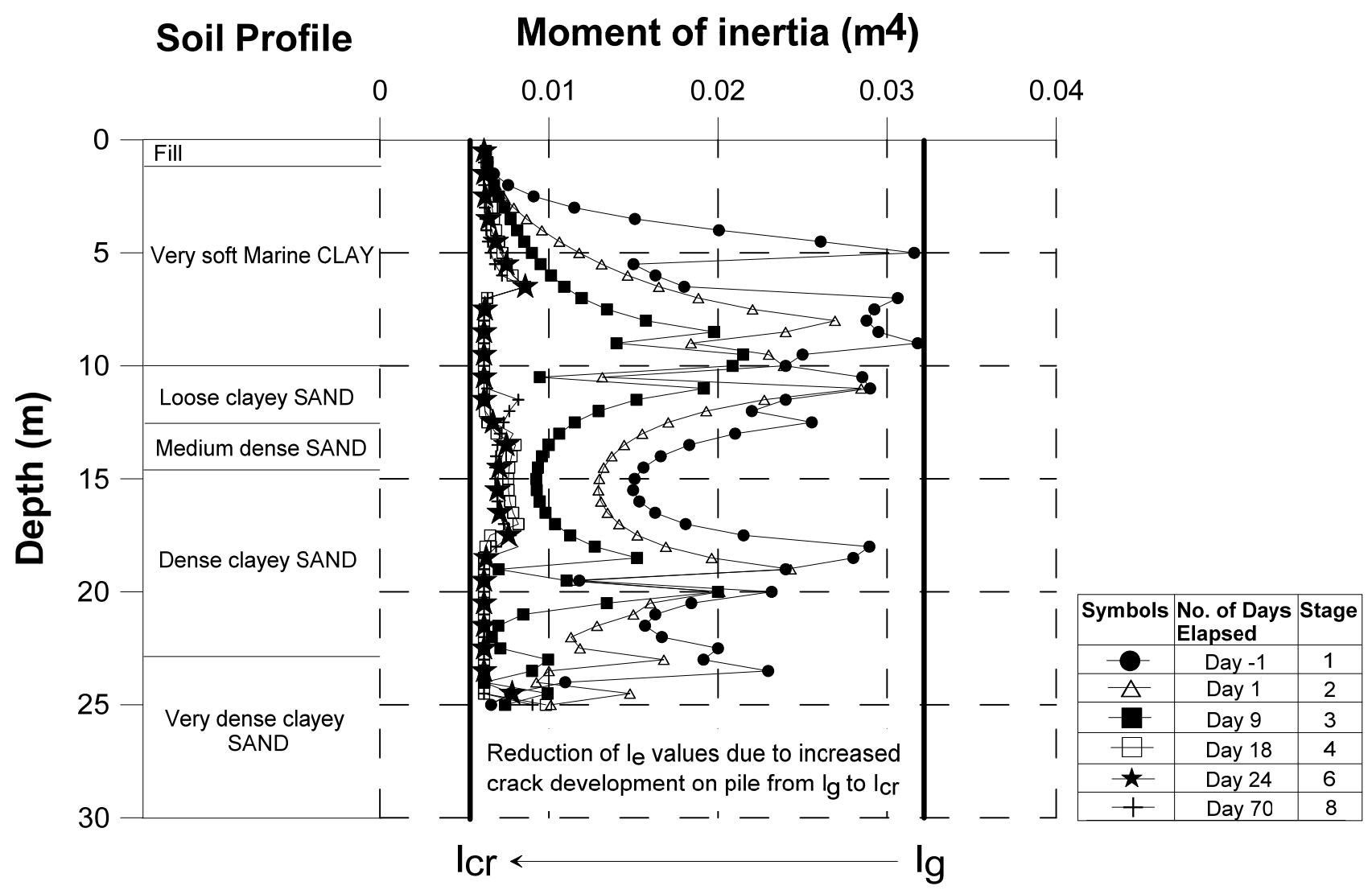

Fig. 9. Computed profiles of effective moment of inertia, $I_{e}$ along the instrumented rear pile over the excavation 


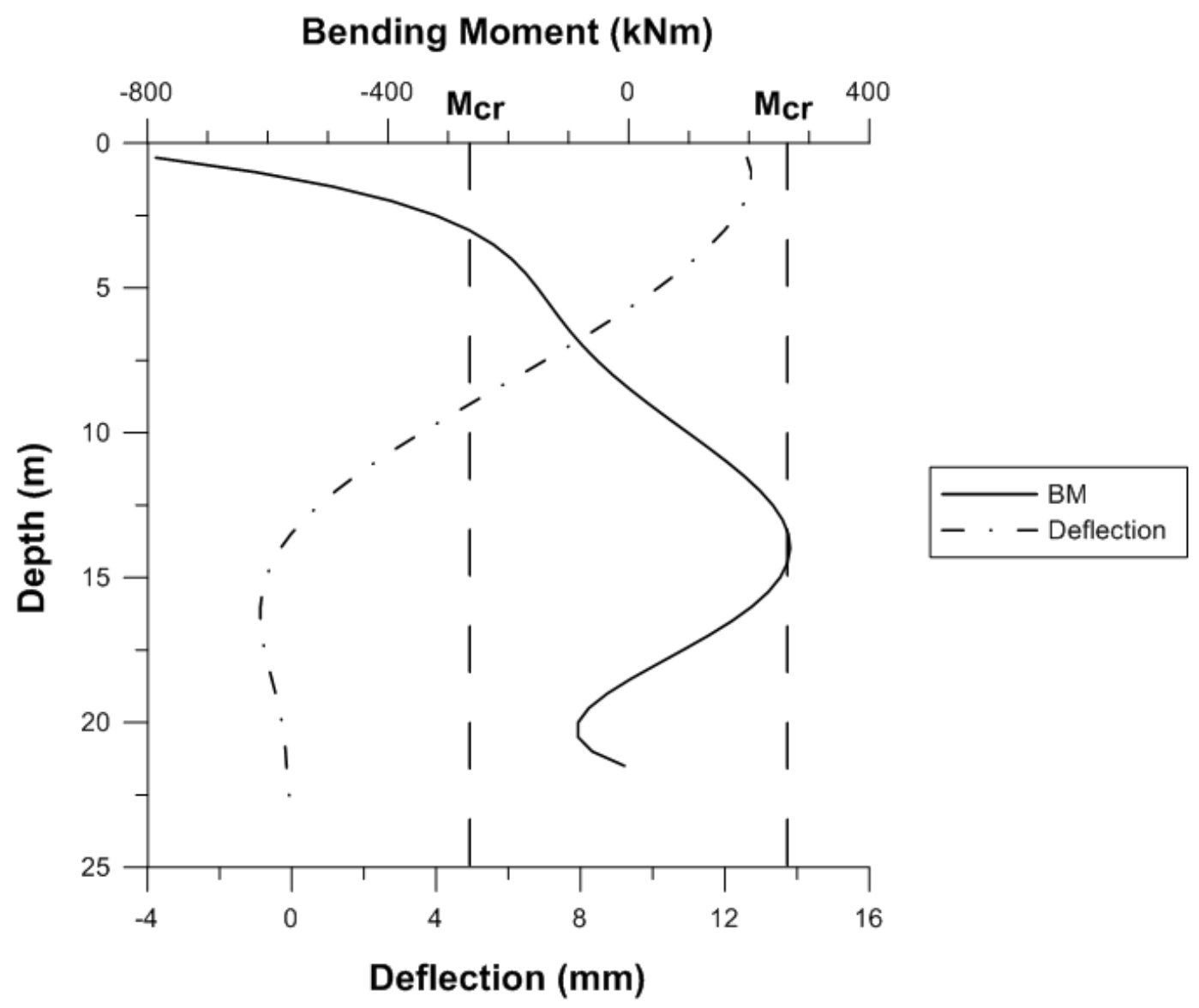

Fig. 10. Back-analyzed pile deflection and bending moment profiles that initiate cracking 


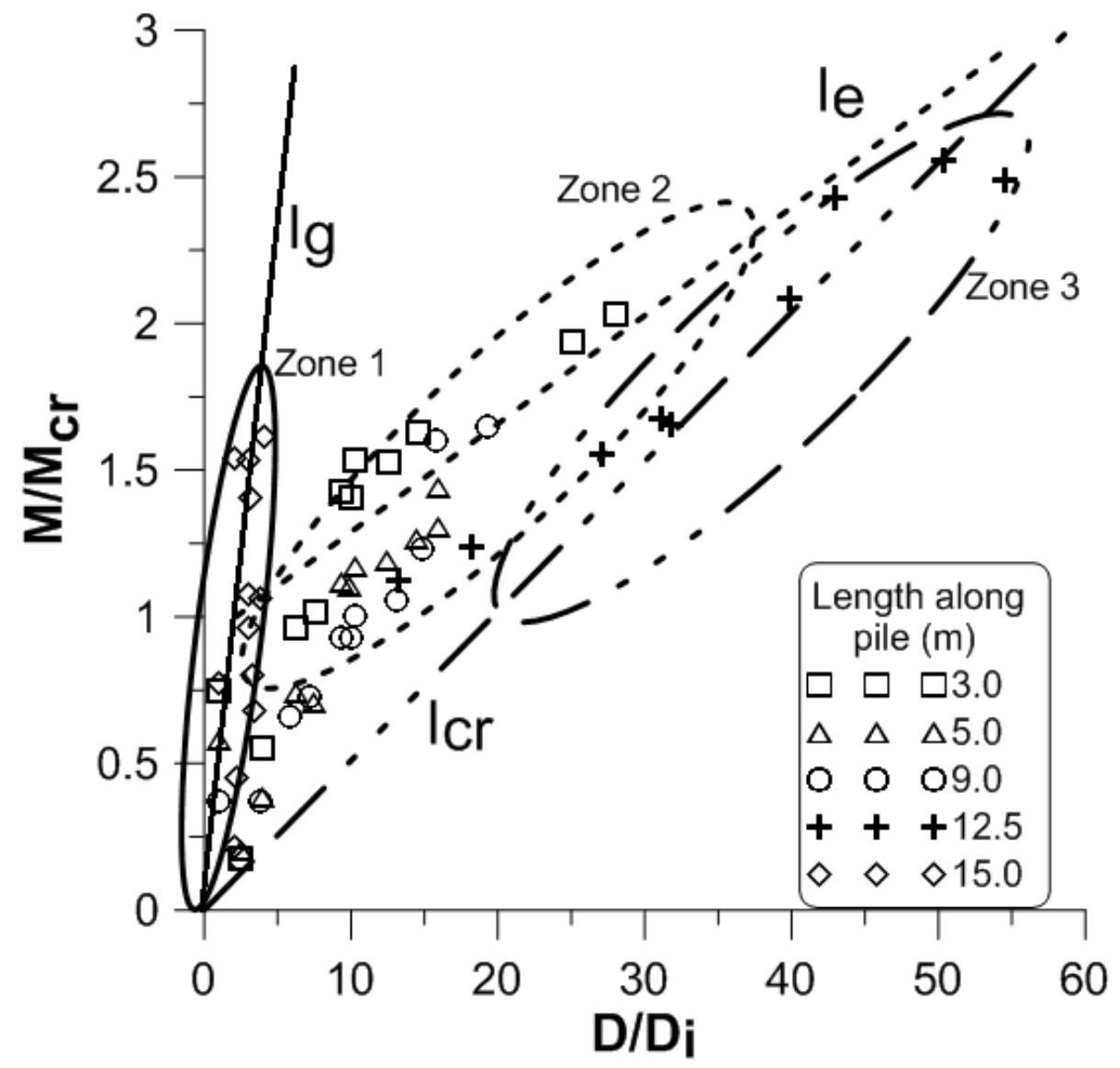

Fig. 11. Interpreted bi-linear moment-deflection curve 


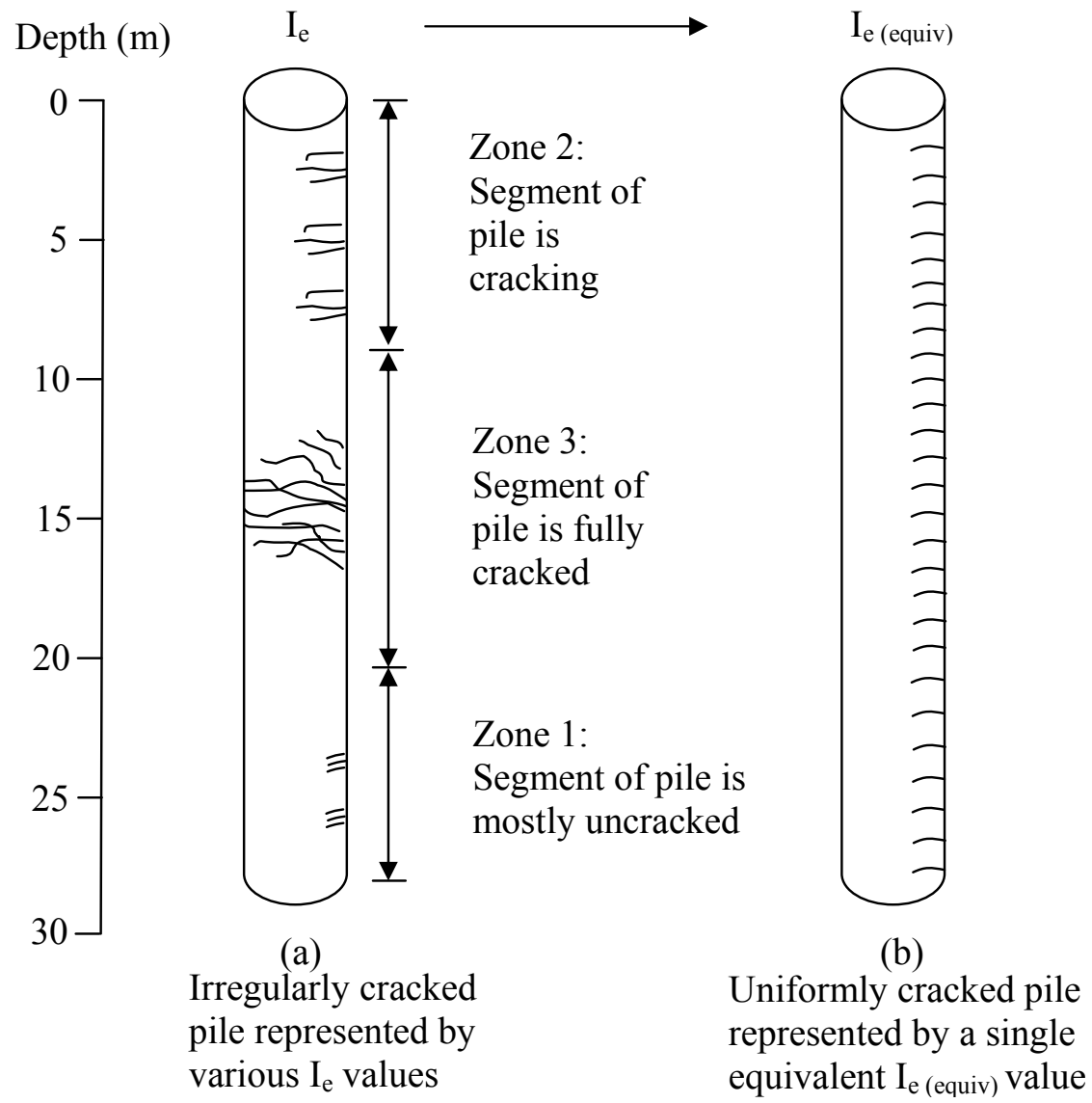

Fig. 12. (a) Possible development of different crack intensities on the instrumented pile and (b) an idealized cracked pile used for back-analysis 


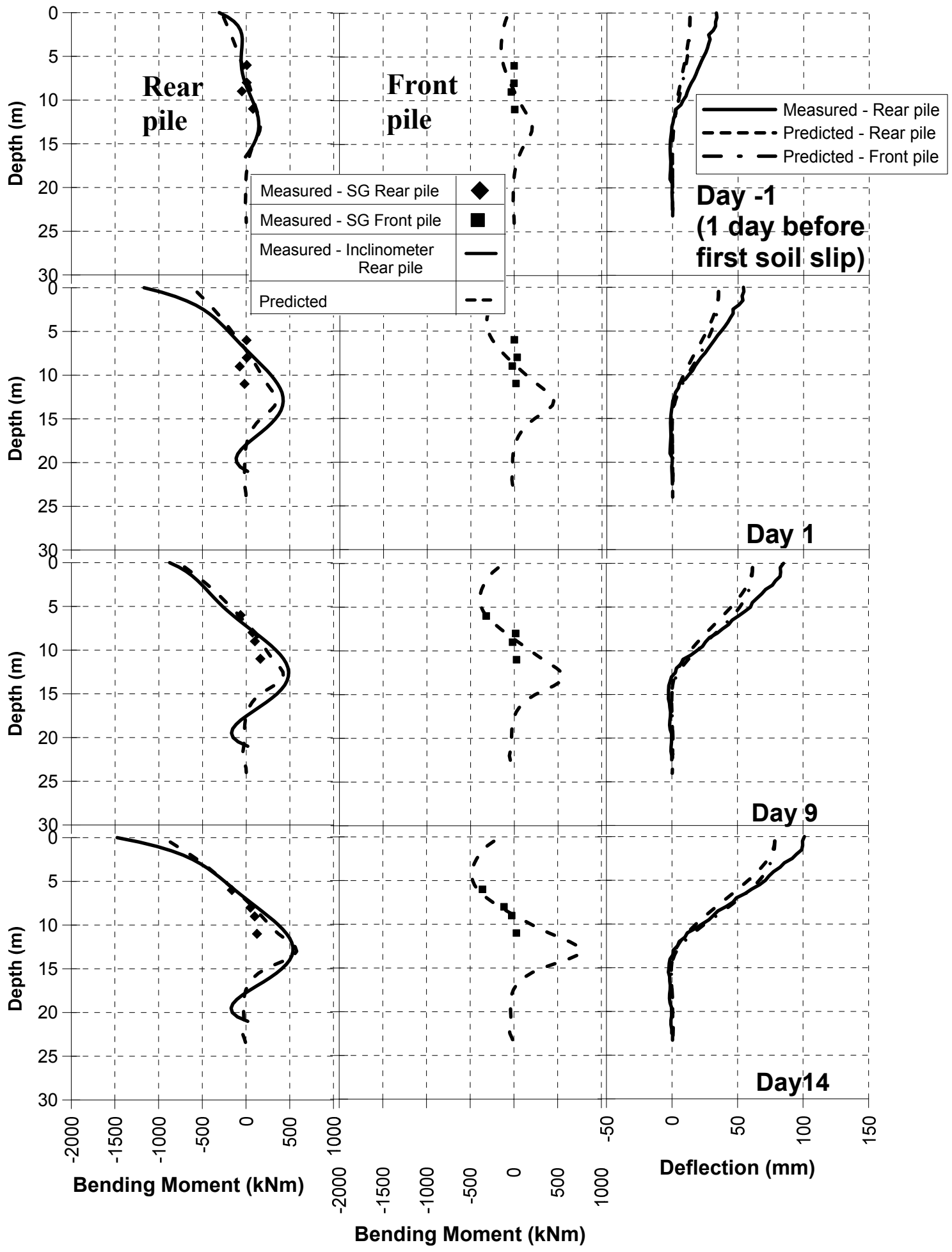

Fig. 13. Selected measured and predicted pile bending moment and deflection profiles based on computed average $\mathrm{I}_{\text {e(equiv) }}$ before and on Day 14 


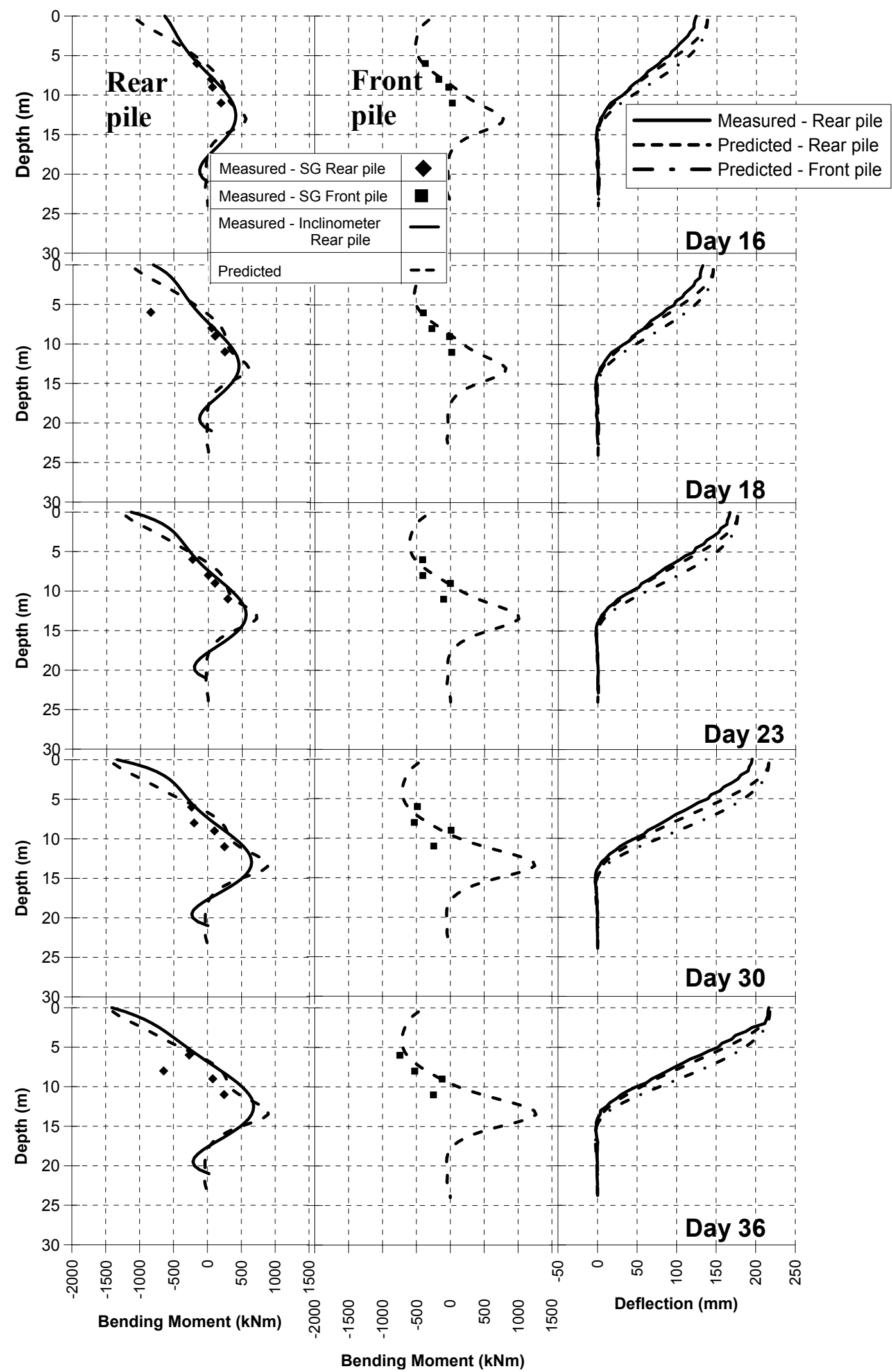

Fig. 14. Selected measured and predicted pile bending moment and deflection profiles based on $\mathrm{I}_{\mathrm{cr}}$ after Day 15 


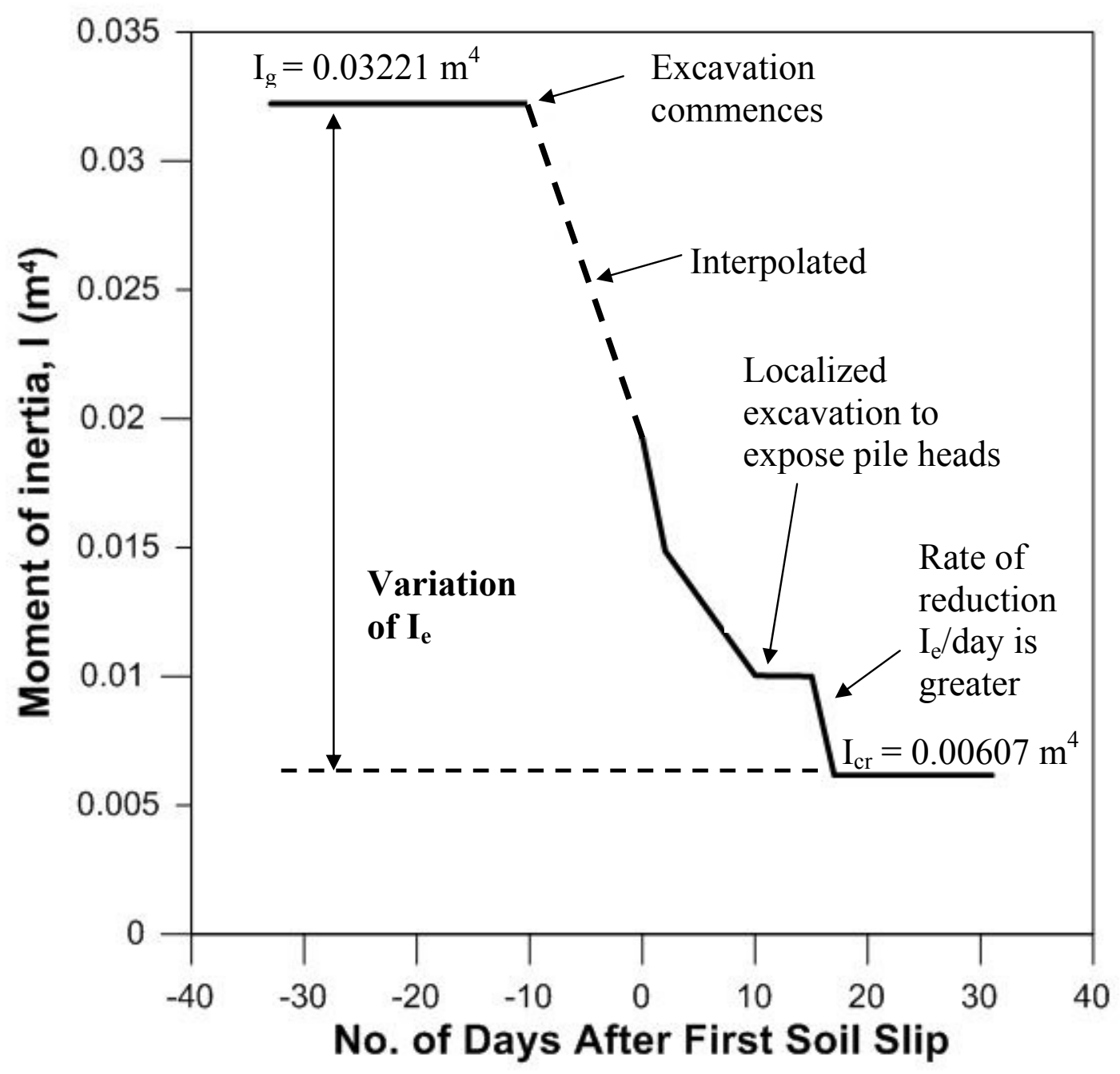

\begin{tabular}{|l|l|l|l|l|l|l|l|}
\hline Construction stage: & 1 & 2 & 3 & 4 & 5 & 6 & 7 \\
\hline
\end{tabular}

Fig. 15. Deterioration of pile moment of inertia after soil slip 


\section{List of Figures}

Fig. 1. Plan view showing the locations of instruments and instrumented pile group at the site

Fig. 2. Interpreted subsurface soil profile at site

Fig. 3. Plan and elevation views of instrumented pile group with respect to the slope excavation

Fig. 4. Layout of instruments attached to reinforcement cages of the bored piles

Fig. 5. Timeline of excavation works

Fig. 6. Slope failure that unexpectedly occurred next to the instrumented pile group (Day 0)

Fig. 7. Measured (a) rear pile deflection and (b) lateral soil movement profiles over the excavation period

Fig. 8. Measured lateral pile deflection and soil movements at various depths over the excavation period

Fig. 9. Computed profiles of effective moment of inertia, $I_{e}$ along the instrumented rear pile over the excavation period

Fig. 10. Back-analyzed pile deflection and bending moment profiles that initiate cracking

Fig. 11. Interpreted bi-linear moment-deflection curve

Fig. 12. (a) Possible development of different crack intensities on the instrumented pile and (b) an idealized cracked pile used for back-analysis

Fig. 13. Selected measured and predicted pile bending moment and deflection profiles based on computed average $\mathrm{I}_{\mathrm{e}(\mathrm{equiv})}$ before and on Day 14

Fig. 14. Selected measured and predicted pile bending moment and deflection profiles based on $\mathrm{I}_{\mathrm{cr}}$ after Day 15

Fig. 15. Deterioration of pile moment of inertia after soil slip 


\section{List of Tables}

Table 1. Computed average equivalent effective moment of inertia, $\mathrm{I}_{\mathrm{e}(\text { equiv) }}$ and fully cracked moment of inertia, $\mathrm{I}_{\mathrm{cr}}$

Table 2. Measured average strain gage readings used for bending moment interpretation 